\title{
A Comprehensive Study on Prevalence of Myopia in School Going Children
}

\author{
Dr. Swaroop Chand Bhansali ${ }^{1}$, Dr. R. Ravi Sunder ${ }^{2 *}$, Dr. Goteti Subbarao ${ }^{3}$ \\ ${ }^{1}$ Associate Professor, Department of Physiology, GIMSR, Rushikonda, Visakhapatnam, Andhra Pradesh 530045, India
${ }^{2}$ Professor, Department of Physiology, GIMSR, Rushikonda, Visakhapatnam, Andhra Pradesh 530045, India
${ }^{3}$ Professor \& HOD, Department of Pathology, GIMSR, Rushikonda, Visakhapatnam, Andhra Pradesh 530045, India
}

DOI: $10.36348 /$ SIJAP.2019.v02i10.003 $\quad$ | Received: 30.09 .2019 | Accepted: 07.10.2019| Published: 17.10 .2019

*Corresponding author: Dr. R. Ravi Sunder

Abstract

Myopia is one of the commonest manifestations affecting school going children. Excessive use of gadgets forms the prime cause apart from the other cause like malnutrition, economic status or genetic conditions. The aim is to study the prevalence of myopia in school children in Visakhapatnam, Andhra Pradesh. With required permissions from the school authorities, five schools were enrolled in the study. 1738 school children of classes $6^{\text {th }}-10^{\text {th }}$ with age ranging from 9-15 years were registered. There were 982 boys and 756 girls. The method of examination has been clearly explained to them. The results were represented graphically. The prevalence of myopia from the present study from the students of Visakhapatnam, Andhra Pradesh was 7.30\%. Girls were more affected $8.33 \%$. When the socio economic status was considered, more students from low socio economic group were found to be affected with myopia. The maximum number of students having myopia was in the age group of 12 years. The students were addressed and the results were explained to them. They were adviced the required measures to prevent further progress of the condition. The students with symptoms were suggested for an Ophthalmic consultation.

Keywords: Myopia, school children, visual morbidity, screening, gadgets.

Copyright @ 2019: This is an open-access article distributed under the terms of the Creative Commons Attribution license which permits unrestricted use, distribution, and reproduction in any medium for non-commercial use (NonCommercial, or CC-BY-NC) provided the original author and source are credited.

\section{INTRODUCTION}

Myopia is that form of refractive error wherein parallel rays of light come to focus in front of the pigment layer of the retina when the eye is at rest. This may be due to the anatomical variation in the shape of the eyeball or the curvatures of cornea or lens. Myopia or short-sightedness is evolving out to be the commonest condition affecting people to such an extent that approximately half of the individuals in this planet tend to be short-sighted by the year 2050, as research suggests [1]. Von-Graefe 1950 was the first to correlate the ophthalmoscopic and degenerative changes of pathological myopia [2]. This has been at increased risk to those who read books or watch television or other gadgets at a close distance apart from the other causes like malnutrition or genetic condition running in the families. In India, refractive errors are the second major cause of visual morbidity, the second cause of low vision and the most common reason for a patient to consult an ophthalmologist [3]. About $13 \%$ of the Indian population is in the age group of 6-15 years, with a school enrolment rate $30 \%$ [4]. A study reveals the types of refractive errors in 4-5 years of age of 1000 eyes are simple myopia-16.7\% and myopia with astigmatism-2.9\% [5]. The prevalence of myopia has been reported to be as high as $70-90 \%$ in some Asian population [6], $80 \%$ in Taiwanese school children [7]. Fan et al., [8] screened 7,560 Chinese children and reported myopia as the most common refractive error and found in $36.7 \%+2.87 \%$ of children. Uzma etal conducted a study in Hyderabad and concluded periodic visual screening programs and primary eye care by trained health care personnel in elementary schools will help to detect early diagnosis of myopia and common ocular diseases in school children [9]. The present study is done to screen the school children of Visakhapatnam to analyze the prevalence of myopia.

\section{MATERIALS \& METHODS}

The screening for myopia has been done in school going children between the age group 9-15 years $\left(6^{\text {th }}-10^{\text {th }}\right.$ standards $)$. The present study was conducted on 1738 school going children. The schools included were two government and three private. After taking the required permissions from the school authorities, appointments were fixed and each school was visited on 
the intimated date during its working hours. 982 boys and 756 girls participated in the study. With the assistance of the class teacher, the preliminary data like name, age, gender, class, socio-economic status was collected. The process of external examination of the eye was explained to the students. External examination was done with torch to detect any diseases of the adnexa and anterior segment of the eye. Simultaneously cover test was done to assess the muscle balance. Each student was made to stand at a distance of 6 meters from the Snellen's chart to check the visual acuity.

When the student was unable to read $6 / 6$ on snellen's chart, a pin hole test was done and visual acuity was recorded to note the improvement if any.Vision of the children who were using glasses were tested both with and without glasses. The near vision test, with the standard near vision charts, was carried out at a distance of $33 \mathrm{~cm}$.

\section{RESULTS}

The study group comprised of 1738 students (boys- $982 \&$ girls 756). The refractive errors were found in 329 students. The number of students detected with myopia was 127 . Girls were more in number when compared to boys. The prevalence of myopia in the study was $7.30 \%$. When the socio economic status was considered, more number of students was found to be affected with myopia from low socio economic group when compared to other groups. The results were plotted in the following tables and graphs.

Table-1: \% prevalence of myopia from the study and gender wise distribution

\begin{tabular}{|l|l|l|l|l|l|}
\hline S No & Students examined & Number & Students with myopia & Number & \% prevalence \\
\hline 1. & Boys & 982 & Boys & 64 & 6.51 \\
\hline 2. & Girls & 756 & Girls & 63 & 8.33 \\
\hline 3. & Total & 1738 & Total & 127 & 7.30 \\
\hline
\end{tabular}

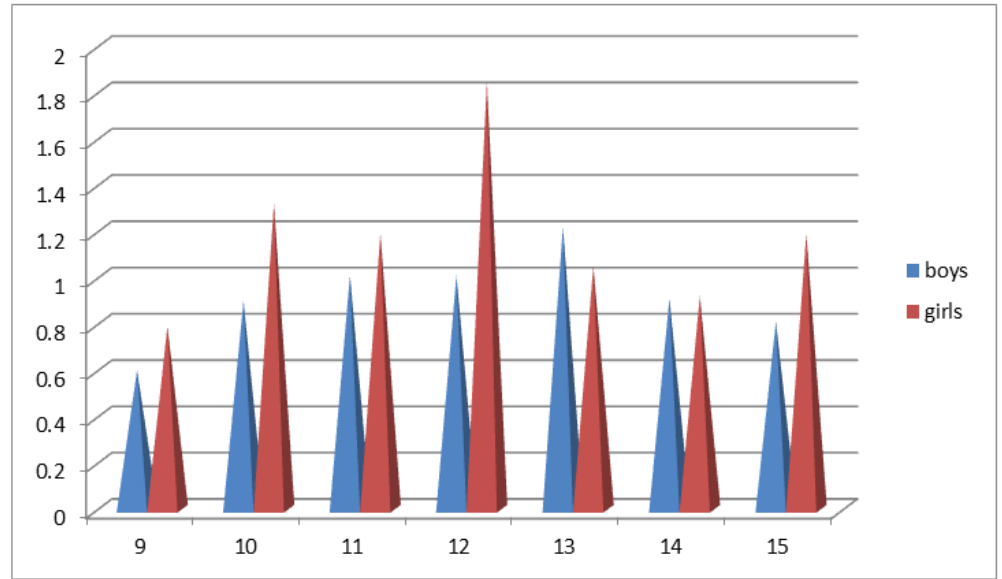

Graph-1: Age wise \% prevalence of myopia in relation to gender

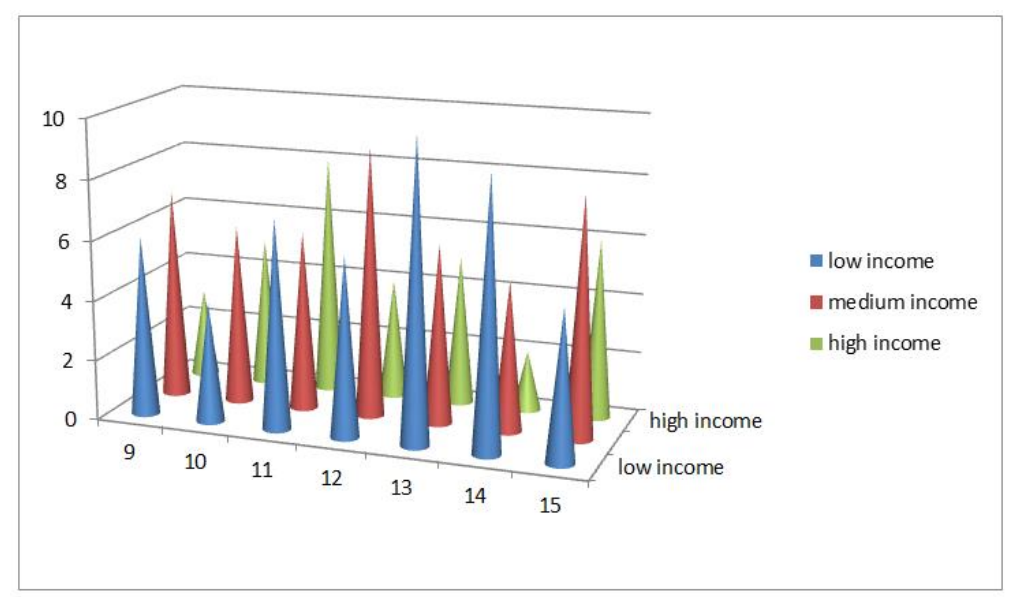

Graph-2: Bar chart showing the prevalence of myopia in relation to the socio economic status

\section{DISCUSSION}

Myopia or short sightedness is considered to be the commonest form of refractive errors affecting the school going children. Spending more time at near work and insufficient outdoor activity are the causes apart from the genetic and nutritional factors. A study done on Chinese school students [10] reported the prevalence of myopia to be $52.02 \%$. A report on Americal children 
concluded the prevalence of myopia to be $41.9 \%$ [11]. A report from India [12] declared the prevalence of myopia to be $21.1 \%$. Refractive errors are often been neglected during routine screening tests done for school children.these are the preventable and easily curable conditions when detected early. If left undiagnosed or untreated they may lead to visual morbidity. The present study reports the prevalence of myopia in school children from $6^{\text {th }}-9^{\text {th }}$ classes with age ranging from 9-15 years. The prevalence of myopia is found to be $7.30 \%$ and is predominantly seen in girls. When the socio economic status was considered, it is more prevalent in low income group. Highest prevalence of myopia was detected in 12 years age group. The study group has been adviced the preventive measures to control further progression. Those presented with symptoms were suggested for an Ophthalmic consultation.

\section{CONCLUSION}

Myopia has been found to affect the school children age ranging from 9-15 years, highest prevalence was seen in 12 years age group. Girls were affected more than boys. When the socio economic status was considered, the low socioeconomic group had more prevalence of myopia. The study group was adviced to follow certain preventive measures.

\section{REFERENCES}

1. Available from: https://www.allaboutvision.com/enin/conditions/myopia/

2. Duke-Elder, S., \& Abrams, D. (1970). Pathological myopia. System of Ophthalmology, Ophthalmic Optics and Refraction. Vol. V. London: Henry Kimpton.

3. Present status of national programme for control of blindness (NPCB), New Delhi. (1995). Directorate General of Health Service, Ministry of Health and Family Welfare, 1992. 16(2), 1995. World Health Forum.
4. Health Information India-1990 New Delhi. (1995). Central Bureau of Health Intelligence, Directorate General of Health Services, Ministry of Health and Family Welfare. World Health Forum. 16(2).

5. Dunstan Med, Officer, London. 48,111(1932) Brit.J.Ophtal,18;404 (1934)

6. Pan, C. W., Ramamurthy, D., \& Saw, S. M. (2012). Worldwide prevalence and risk factors for myopia. Ophthalmic and Physiological Optics, 32(1), 3-16.

7. Lin, L. L., Shih, Y. F., Hsiao, C. K., \& Chen, C. J. (2004). Prevalence of myopia in taiwanese schoolchildren: 1983 to 2000. Ann Acad Med Singapore, 33:27-33.

8. Fan, D. S., Lam, D. S., Lam, R. F., Lau, J. T., Chong, K. S., Cheung, E. Y., ... \& Chew, S. J. (2004). Prevalence, incidence, and progression of myopia of school children in Hong Kong. Investigative ophthalmology \& visual science, 45(4), 1071-1075.

9. Uzma, N., Kumar, B. S., Salar, B. K. M., Zafar, M. A., \& Reddy, V. D. (2009). A comparative clinical survey of the prevalence of refractive errors and eye diseases in urban and rural school children. Canadian Journal of Ophthalmology, 44(3), 328-333.

10. Sun, J. T., An, M., Yan, X. B., Li, G. H., \& Wang, D. B. (2018). Prevalence and related factors for myopia in school-aged children in Qingdao. Journal of ophthalmology, 2018.

11. Theophanous, C., Modjtahedi, B. S., Batech, M., Marlin, D. S., Luong, T. Q., \& Fong, D. S. (2018). Myopia prevalence and risk factors in children. Clinical ophthalmology (Auckland, NZ), 12, 1581-1587.

12. Singh, N. K., James, R. M., Yadav, A., Kumar, R., Asthana, S., \& Labani, S. (2019). Prevalence of Myopia and Associated Risk Factors in Schoolchildren in North India. Optometry and Vision Science, 96(3), 200-205. 